\title{
DIRECTIONS OF THE REPRODUCTION PROCESS TRANSFORMATION IN MODERN RUSSIAN ECONOMY ${ }^{1}$
}

\author{
Alexey M. Tsikin \\ Financial University under the Government of the Russian Federation, Moscow, Russian Federation
}

\begin{abstract}
The article is devoted to the analysis of the modern aspects of the reproduction process transformation in the context of the development of Russian economy. To achieve this goal, the work analyzes the transformation of the stages of social reproduction, as well as evaluates its impact on the relevant process scheme. It has been established that today each stage is undergoing significant changes, in particular, production methods and manufactured products are improved, the distribution of resources between sectors of economy is changing, exchange processes are expanding, and goals and methods of consumption are transformed. Among the features of modern reproduction models, the growth of the non-material sphere due to the development of the service market and their integration with material production, the implementation of the reproduction of a social product based on innovative production and Schumpeter competition, the establishment of human capital being a source of innovation as the basis of the reproduction process, should be noted. The current level of the development of Russian economy and promising requirements for the reproduction process in the neo-industrial model lead to the need to separate the stage of institutional and technological design of the product life cycle and to include a separate phase of scientific training in the traditional chain of stages of the social reproduction process. The results of the work can be used as a supplement to modern neoclassical theories and re-actualized political and economic methodologies.
\end{abstract}

Key words: social reproduction, Russian economy, competitiveness, economic growth, technological modes of production.

Citation. Tsikin A.M. Directions of the Reproduction Process Transformation in Modern Russian Economy. Journal of Volgograd State University. Economics, 2020, vol. 22, no. 2, pp. 17-27. (in Russian). DOI: https://doi.org/ 10.15688/ek.jvolsu.2020.2.2

УДК 330.31

Дата поступления статьи: 22.01.2020

ББК 65.01 Дата принятия статьи: 13.03.2020

\section{НАПРАВЛЕНИЯ ТРАНСФОРМАЦИИ ВОСПРОИЗВОДСТВЕННОГО ПРОЦЕССА В СОВРЕМЕННОЙ РОССИЙСКОЙ ЭКОНОМИКЕ ${ }^{1}$}

\author{
Алексей Максимович Цикин \\ Финансовый университет при Правительстве Российской Федерации, г. Москва, Российская Федерация
}

Аннотация. Статья посвящена анализу современных аспектов трансформации воспроизводственного процесса в контексте развития российской экономики. Для достижения поставленной цели в работе выполнен анализ трансформации стадий общественного воспроизводства, а также оценено ее влияние на общую схему процесса. Установлено, что сегодня каждая стадия претерпевает значительные изменения, в частности, совершенствуются способы производства и выпускаемая продукция, изменяется распределение ресурсов между секторами экономики, расширяются процессы обмена, а также трансформируются цели и способы потребления. В числе особенностей современных воспроизводственных моделей следует отметить рост нематериальной сферы за счет развития рынка услуг и их интеграции с материальным производством, осуществление воспроизводства общественного продукта на базе инновационной продукции и шумпете- 
ровской конкуренции, становление основой воспроизводственного процесса человеческого капитала как источника инноваций. Текущий уровень развития российской экономики и перспективные требования к воспроизводственному процессу в неоиндустриальной модели приводят к необходимости выделения стадии институционально-технологического проектирования жизненного цикла товара и включения отдельной фазы научной подготовки производства в традиционную цепочку стадий процесса общественного воспроизводства. Результаты работы могут использовать как дополнение к современным неоклассическим теориям и реактуализированной политико-экономической методологии.

Ключевые слова: общественное воспроизводство, российская экономика, конкурентоспособность, экономический рост, технологические уклады.

Цитирование. Цикин А. М. Направления трансформации воспроизводственного процесса в современной российской экономике // Вестник Волгоградского государственного университета. Экономика. - 2020. T. 22, № 2. - C. 17-27. - DOI: https://doi.org/10.15688/ek.jvolsu.2020.2.2

\section{Введение}

Диалектическое движение национальных экономик оказывает непосредственное воздействие на общественное воспроизводство за счет трансформации всех стадий процесса. Изменение направления и особенностей протекания каждой стадии непосредственно связано с переходом национальных экономик к новым технологическим укладам [Глазьев, 1993]. В контексте преобразования воспроизводственного процесса следует выделить следующие особенности пятого (информационного) и шестого (неоиндустриального) уклада.

Пятый технологический уклад в отношении присущих производственных процессов может быть разделен на три стадии, непосредственно воздействующие на общественное воспроизводство [Климова, 2010, с. 14-15]:

- автоматизированное производство с математическим описанием технологических процессов и управлением ими посредством компьютеризированных систем;

- гибкие производственные системы, сопряженные с автоматизированными системами проектирования, станками с числовым программным управлением и автоматизированными системами управления технологическими процессами;

- интегрированные производственные системы, функционирующие на основе гибких производственных систем, объединенных в единый комплекс.

Шестой технологический уклад характеризуется широким внедрением нано-, биои «зеленых» технологий, широкой цифровизацией экономики. В числе приоритетных направлений неоиндустриального уклада выде- ляют гибкую автоматизацию производства, космические технологии, производство конструкционных материалов с заранее заданными свойствами, расширение применения возобновляемых источников энергии [Авербух, 2010, с. 160].

В настоящее время российская экономика в основном находится на третьем-четвертом технологическом укладе с перспективой перехода к наиболее эффективным направлениям пятого и шестого укладов в ряде отраслей экономики. Подобная многоукладность российской экономики приводит к многочисленным проблемам в общественном воспроизводстве, связанным с деформацией воспроизводственной структуры, неоднородностью пространственной системы, сырьевой направленностью, несбалансированностью рынка труда и неэффективностью использования ресурсных факторов [Коновалова, 2009, с. 90]. В связи с этим анализ соответствующей трансформации стадий общественного воспроизводства и традиционной схемы процесса в контексте реализации неоиндустриальной модели развития является актуальной задачей.

Поставленные задачи исследования обусловили необходимость выделения двух разделов, связанных с оценкой особенностей стадий общественного воспроизводства в российской экономике и трансформацией традиционной схемы общественного воспроизводства. Первый раздел содержит результаты анализа трансформации стадий производства, распределения, обмена и потребления в условиях перехода к новым технологическим укладам. Второй раздел направлен на разработку рекомендаций по модификации 
воспроизводственного процесса на основе анализа текущего уровня развития российской экономики в контексте неоиндустриального развития.

\section{Особенности стадий общественного воспроизводства} в российской экономике

Стадия производства. С точки зрения генетического подхода стадия производства в настоящее время претерпевает наиболее значимые изменения. В индустриальной модели экономического развития (соответствующей третьему и четвертому технологическим укладам) основу составляет материальное производство. С переходом к пятому и шестому технологическим укладам все большее значение приобретает нематериальное производство и в частности сфера высокотехнологичных услуг.

Последние характеризуются неценовой (шумпетеровской) конкуренцией, что способствует повышению уровня жизни производителей и в целом населения страны и выступает основой конкурентоспособности национальной экономики согласно современным представлениям. В числе таких услуг следует особо выделить информационные технологии, в которых товар и услуга часто выступают воедино. Не меньшее значение в неоиндустриальной модели имеют услуги, связанные с социальным обеспечением. Развитие сферы ЖКХ и коммунально-бытового сектора, образования, здравоохранения и культуры обеспечивает повышение уровня социальных факторов конкурентоспособности. Важно отметить, что связь элементов в этом процессе двусторонняя. Кроме того, в современных условиях отчетливо прослеживается тенденция к интеграции материального производства и сферы высокотехнологичных услуг [Mont, 2002].

В материальном производстве при переходе национальных экономик к новым технологическим укладам также происходят существенные изменения, которые целесообразно рассматривать в двух аспектах. С одной стороны, факторы научно-технического прогресса способствуют совершенствованию технологий, которые лежат в основе производства продукции. С другой стороны, в результате разви- тия национальных экономик создаются новые, уникальные или лучшие продукты.

При упрощенном рассмотрении первый аспект трансформации стадии производства состоит в сокращении длительности отдельных технологических операций. Сокращение длительности операций и соответствующее повышение экономической эффективности процесса без второго аспекта (создания новых продуктов) на практике может привести к снижению конкурентоспособности. Если смоделировать ситуацию, в которой производительность всей промышленности увеличилась условно в два раза, то и численность работающих, и совокупный спрос также уменьшатся в два раза. Для удовлетворения нового спроса потребуется в два раза меньше фирм. В пределе эта ситуация приведет к монополизации рынка и росту безработицы. Теоретические ситуации, при которых снижение цены на выпускаемую продукцию вызывает расширение спроса при росте выпуска или понижение издержек при прежней цене, на практике, к сожалению, редко находят подтверждение в масштабах национальной экономики. В российских условиях анализируемый аспект трансформации стадии производства в первую очередь относится к сырьевым товарам и продукции низкого передела. В этом случае рынок сбыта товарной продукции в основном расширяется за счет зарубежных стран, что приводит к падению мировых цен, и, следовательно, выручки национальных производств [Кастро, 1983].

Монополистическим тенденциям способствует также ценовой тип конкуренции, характерный для описываемого процесса в случае производства индустриальных товаров. В такой постановке промышленное производство ставит главной целью снижение операционных затрат. При исчерпании резервов снижения производственных расходов за счет технологических возможностей единственным фактором дальнейшего роста конкурентоспособности является снижение уровня оплаты труда работников. Таким образом, ценовая конкуренция приводит к снижению заработных плат и уровня жизни персонала предприятия (или населения страны при рассмотрении в национальном масштабе). Более того, ориентация исключительно на снижение производ- 
ственных издержек способствует проявлениям экстерналий, связанным со снижением уровня экологической и производственной безопасности, эксплуатацией труда женщин и детей и другими эффектами.

Второй аспект влияния развития национальных экономик на стадию производства более значим с точки зрения формирования основы долгосрочного экономического роста. При ориентации национального производства на выпуск новых товаров и услуг стимулируется появление нового спроса и увеличение уровня занятости населения. Новые продукты способствуют установлению на рынке неценовой конкуренции, которая порождает повышение уровня оплаты труда работников и рост уровня жизни населения страны. Следует отметить, что появление новых продуктов и увеличение зарплат даже в некоторых отраслях промышленности способствует повышению уровня жизни населения в целом (даже независимо от индивидуальной производительности труда). Так, развитие промышленности и рост зарплат в ней в ведущих странах привели к тому, что в сфере услуг зарплаты также возросли. В результате уровень жизни работников одного профессионального уровня в разных странах существенно отличается [Global Wage Report ..., 2016].

При этом наиболее существенное положительное влияние на экономический рост оказывает одновременная реализация двух рассматриваемых аспектов. Для воплощения в жизнь этого сценария в России назрела необходимость полномасштабной модернизации промышленности. В современных российских условиях модернизация заключается в увеличении наукоемкости производств и научно-технического уровня продукции, расширении сферы использования прорывных технологий, связанных с цифровизацией экономики. Среди таких технологий следует особо отметить адаптивные производственные системы, а также системы машин и коммуникационной техники, характерные для шестого неоиндустриального уклада [Kormishkina et al., 2016].

\section{Стадия распределения}

В условиях необходимости развития российской экономики анализ стадии распреде- ления приобретает особое значение. Современная экономическая ситуация в России характеризуется значительными дисбалансами именно в этой области. Текущая логика функционирования народного хозяйства предполагает вывод материальных благ в офшорные юрисдикции, а также присвоение частным бизнесом природных ресурсов и отчуждение национального хозяйства.

В настоящее время накопленный капитал, который теоретически мог бы и должен был бы направляться на развитие национального хозяйства, используется для вывода в зарубежные страны. В современной российской экономической системе такой вывод капитала осуществляется как путем импорта товаров с высокой добавленной стоимостью, так и за счет вывода денежных средств в офшоры. При этом российский бизнес прибегает к оформлению в офшорных юрисдикциях не только с целью минимизации налогообложения, но для работы в стабильной политической и правовой системах. Результатам преобладающего вывода капитала за рубеж является снижение присвоения собственности и увеличение ее отчуждения.

За счет рассмотренного процесса технологический и интеллектуальный потенциал, накопленный в СССР, не только полноценно не воспроизводится, но и значительно уменьшается. Начиная с 1990-х гг. темпы роста затрат на НИОКР в России значительно отставали от развитых экономик и не обеспечивали замедления технической и технологической деградации отечественных предприятий. Отягчающим производственную деградацию фактором является утрата человеческого капитала в результате эмиграции наиболее конкурентоспособной, экономически и политически активной части населения после распада СССР.

Для полноценного экономического роста необходимо обеспечить эффективное распределение ресурсов между секторами экономики. В российских условиях это конкретизируется в преимущественное направление ресурсов в наукоемкие и высокотехнологичные отрасли, для которых характерна возрастающая отдача [Arthur, 1996]. Кроме того, ориентация на наукоемкие отрасли позволяет перейти к неценовой конкуренции и трансформировать стадию производства лучшим способом. 


\section{Стадия обмена}

В современной экономической системе сфера обмена приобретает большое значение в связи с тем, что полезность товара определяется рынком. При отсутствии сигнала со стороны рынка производство ни одного товара не будет запущено. Если рассматривать обмен, совершаемый на стадии производства, то в числе современных особенностей процесса следует особо упомянуть более широкую специализацию, а также общее расширение процессов обмена между работниками. При рассмотрении обмена как самостоятельной стадии процесса общественного воспроизводства результат процесса способствует обеспечению каждого участника процесса воспроизводства справедливой доле благ, установленной распределением.

Цифровизация экономики способствует значительному снижению транзакционных издержек, возникающих в сфере обмена и связанных со сбором и обработкой информации, формированием управленческих решений и осуществлением контроля. В таких условиях значительно уменьшаются возможности для оппортунистического поведения субъектов рынка, что выражается в снижении уровня неопределенности и рисков, связанных с производством товаров и услуг, а следовательно улучшается эффективность экономики и перспективы повышения уровня жизни населения.

Таким образом, переход к новым технологическим укладам на стадии обмена приводит к повышению согласованности отношений между субъектами, минимизации сбоев в технологических цепочках и упрощению поиска новых поставщиков и потребителей товаров и услуг.

\section{Стадия потребления}

Заключительная стадия общественного воспроизводства, потребление, также подвергается значительным изменениям при переходе к новым технологическим укладам. В частности, изменяются цели и способы потребления, совершенствуется как личное, так и производственное потребление. Последнее при развитии факторов конкурентоспособности становится более рациональным, снижают- ся удельные затраты на производство единицы продукции, повышается экономическая эффективность производственного процесса. Личное потребление также изменяется за счет ориентации на более качественные и экономичные товары и услуги.

Снижение нормы потребления ресурсов при переходе к шестому неоиндустриальному укладу происходит за счет четырех групп эффектов:

- сетевые эффекты, связанные с распространением научно-технических достижений по всей цепочке формирования добавленной стоимости;

- эффект опыта, связанный с повышением эффективности работы персонала при накоплении знаний;

- эффект масштаба, связанный со снижением удельных условно-переменных затрат при росте объемов производства;

- технологические прорывы, связанные с существенным повышением эффективности технологий.

Особенно отчетливо указанные эффекты трансформации стадии потребления выражены в кластерных структурах, для последних характерно широкое использование синергетических эффектов, при которых результат деятельности совокупности фирм кластера превосходит сумму результатов деятельности отдельных организаций [Эггерсон, 2001]. При переходе к новым технологическим укладам на этом уровне наиболее ярко трансформируются организационная структура и размер фирм. Мировой опыт свидетельствует, что эти характеристики непосредственно связаны с инновационной активностью, сопровождающей научно-технический прогресс. С одной стороны, больший размер организации обусловливает возможность привлечения значительных финансовых ресурсов, требуемых для разработки и внедрения новых технологий и продукции. С другой стороны, в крупных организациях совершенствование используемых техник и технологий требует больших затрат времени и денежных ресурсов вследствие необходимости внесения изменений в более сложные технологические процессы [Shefer et al., 2005].

В российских условиях инновационная активность в основном сосредоточена в круп- 
ных фирмах, при этом влияние малых и средних предприятий на научно-технический прогресс становится менее значительным. Одной из наиболее важных причин является низкая доступность кредитных ресурсов, недостаточные собственные денежные средства и отсутствие административного ресурса. Вследствие этого в России наблюдается низкий уровень маркетинговых и организационных инноваций, что входит в противоречие с мировой практикой, согласно которой существует явная корреляционная связь между маркетинговыми, организационными и технологическими нововведениями [Kleinknecht et al., 2002].

Отдельно следует выделить вклад перехода к новым технологическим укладам и сопутствующую новую индустриализацию стран в воспроизводство окружающей среды. С одной стороны, возрождение промышленного потенциала России способно привести к негативным последствиям для природы за счет увеличения производственных мощностей и объемов выбросов, сбросов и размещения отходов производства. С другой стороны, данный негативный эффект, как правило, компенсируется совершенством новых технологических процессов. Например, переход к атомной энергетике при соблюдении правил охраны труда и окружающей среды способствует значительно меньшему загрязнению природы, чем при использовании угольных электростанций. Аналогичны соображения для ТЭЦ на природном газе по сравнению с аналогами на жидком топливе. При этом следует отметить, что для населения каждый новый вид ущерба представляется в силу неизведанности более опасным, чем при использовании традиционных технологий.

Таким образом, тенденции современного технологического развития приводят к изменению содержания стадий общественного воспроизводства. Комплексность перехода к новым технологическим укладам в контексте развития российской экономики заключается в том, что преобразуется весь процесс создания общественного продукта, основное и вспомогательное производство, сущность предметов труда, распределение ресурсов между отраслями и процессы обмена, коренным образом изменяется процесс организации про- изводства, что приводит к трансформации соответствующей воспроизводственной схемы.

\section{Трансформация традиционной схемы общественного воспроизводства в российских условиях}

Современные тенденции в изменении содержания стадий общественного воспроизводства приводят к повышению значимости социальных, трудовых, инновационных и технологических факторов национального развития. Особенно важно рассмотрение данных элементов в контексте перехода к новым технологическим укладам и неоиндустриальной модели развития. Повышенные требования к уровню национальной экономики, предъявляемые современными моделями, требуют проведения анализа российской экономики. При этом в качестве основных элементов соответствующего исследования целесообразно выделение групп показателей и индивидуальных индикаторов в соответствии с рекомендациями [Цикин, 2017].

Выполненные в недавно вышедшей монографии [Проблемы ... , 2019] исследования данных показателей позволяют сформулировать основные выводы относительно текущего уровня развития российской экономики. Качественные характеристики рыночных реформ после распада СССР характеризуются невысоким уровнем и не способствуют дальнейшему развитию экономики, что вносит неопределенность не только в реализацию конкурентных преимуществ России, но и в экономическую безопасность страны. Общий уровень развития национальной экономики относительно невысокий, динамика показателей конкурентоспособности разнонаправлена и показывает недостаточную эффективность государственной экономической политики. Достигнутые в настоящее время макроэкономические показатели (уменьшение темпов инфляции, стабилизация курса рубля, рост количественных показателей реализации товаров и услуг) не являются фундаментальной основой для экономического роста и остаются крайне подверженными факторам внешнего окружения.

Рассмотренные особенности современного общественного воспроизводства в России и мире, а также текущий уровень разви- 
тия российской экономики обусловили необходимость включения в традиционную цепочку стадий процесса общественного воспроизводства нового элемента: научной подготовки производства (рис. 1). Особенно остро ощутима эта потребность в связи с переходом к перспективным пятому и шестому технологическим укладам, сопровождающимся устойчиво расширенным воспроизводством.

Выделение научной подготовки производства связано в первую очередь с необходимостью перехода к инновационным образцам техники и технологий, затраты на внедрение которых сопоставимы, а зачастую и превосходят расходы на поддержание текущего производства. Основными элементами стадии научной подготовки производства является выполнение научных исследований, опытных конструкторских и технологических разработок, проведение испытаний новых образцов, модернизация технологической базы действующих производств и прочие составляющие.

Систематизируя необходимые элементы стадии научной подготовки производства, целесообразно выделить три основных этапа:

1) научные исследования (НИ), целью которых являются поисковые исследования основных направлений развития техники и технологий в условиях перехода к пятому и шестому технологическим укладам;

2) конструкторские разработки (КР), направленные на создание технологических решений, воплощающих результаты выполненных научных исследований, включая их оптимизацию и адаптацию к действующей производственной структуре;

3) технологическая подготовка (ТП), в ходе которой действующие производства адаптируются ко внедрению передовых образцов техники и технологий, разработанных на предыдущих стадиях научной подготовки производства.
В качестве схемы реализации стадии научной подготовки производства можно использовать адаптированную схему принятия решений [Kulkarni et al., 1988, p. 152], предложенную на рисунке 2 . Основным элементом данной схемы является человеческий капитал, выраженный в знаниях и участвующий на каждой стадии научной подготовки производства. Наибольшее значение для реализации предлагаемой схемы имеет стадия проведения научных исследований, на которой закладываются основные стратегические решения по развитию производства и воспроизводственного процесса в целом. Данное обстоятельство предопределяет особую роль человеческого капитала и знаний в развитии национальной экономики. Экономический рост в таких условиях напрямую связан с улучшением социальных, инновационных, технологических и прочих ранее рассмотренных факторов, что согласуется с выявленными особенностями трансформации стадий общественного воспроизводства.

Помимо выделения стадии научной подготовки производства, свидетельствующей о все возрастающем влиянии НИОКР на воспроизводственный процесс, в исследовании С.А. Толкачева и А.Ю. Теплякова показывается необходимость выделения стадии институционально-технологического проектирования (ИТП) жизненного цикла товара, на которой формируется институционально-инновационная среда [Толкачев и др., 2012, с. 155]. Этот процесс представляется объективным вследствие возрастающей роли инновационной (шумпетеровской) конкуренции в формировании конкурентоспособности национальных экономик. Уход от совершенной (ценовой) конкуренции способствует формированию экономической прибыли агентов, которая может быть использована для модернизации производств и внедрения инноваций в технологический процесс.

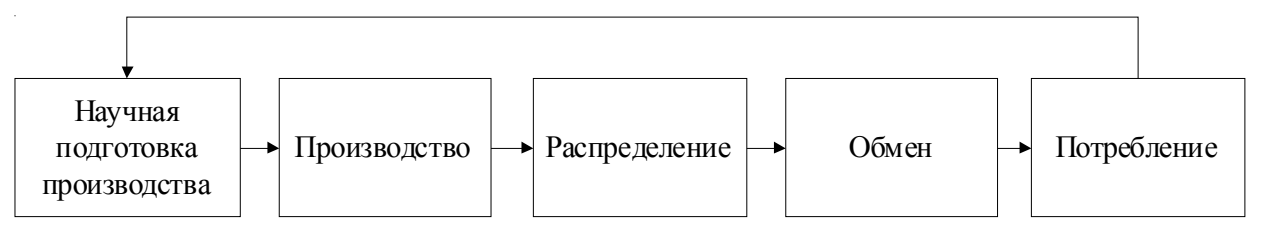

Рис. 1. Стадии общественного воспроизводства в неоиндустриальной экономике Примечание. Составлено авторами по материалам исследования. 


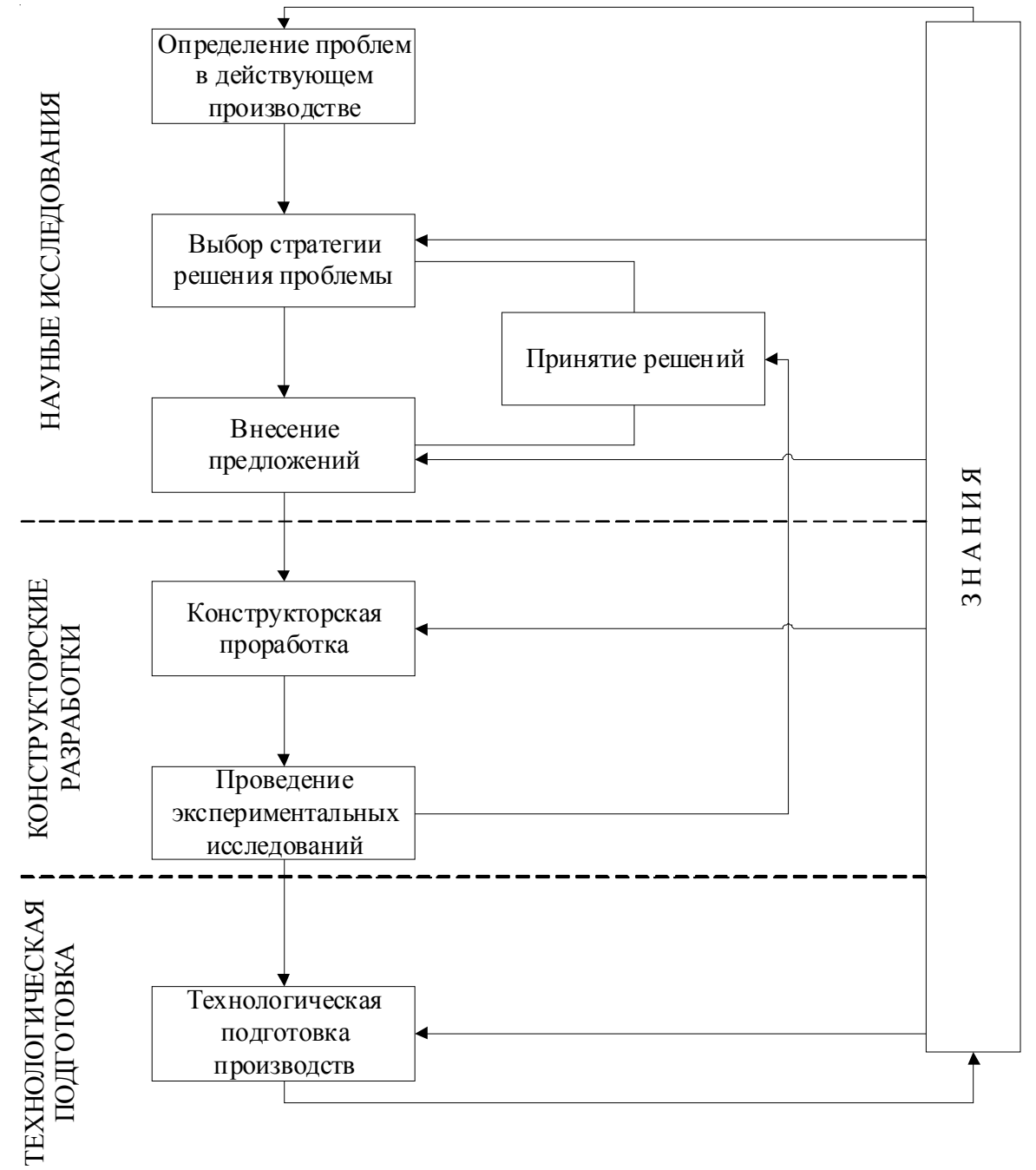

Рис. 2. Общая схема реализация стадии научной подготовки производства

Примечание. Составлено авторами по материалам исследования.

В рассматриваемых обстоятельствах рынки находятся в ситуации постоянного неравновесия в противовес классическим постулатам о равновесном состоянии [Thaler, 2015]. В контексте российских условий данный процесс позволяет преодолеть периферийный характер отечественной экономики и специализироваться на реализации товаров и услуг с возрастающей отдачей, для производства которых необходимо широкое внедрение инноваций. В воспроизводственном аспекте конкуренция при этом смещается из стадии производства и научной подготовки воспроизводства в сферу формирования институциональных преимуществ развития предприятий, что позволяет дополнительно детализировать схему общественного воспроизводства (см. рис. 3).

\section{Заключение}

В результате выполненных в работе исследований установлено, что каждая стадия процесса общественного воспроизводства в России сегодня претерпевает значительные изменения. Наибольшая трансформация характерна для стадии производства, на которой расширяется сфера нематериального производства, происходит его интеграция с материальным производством, снижается длительность технологических операций и эксплуатационные затраты, появляются новые инновационные продукты. В стадии распределения для современной российской экономики характерны значительные дисбалансы, связанные с несправедливым распределением ресурсов между рыночными агентами и 


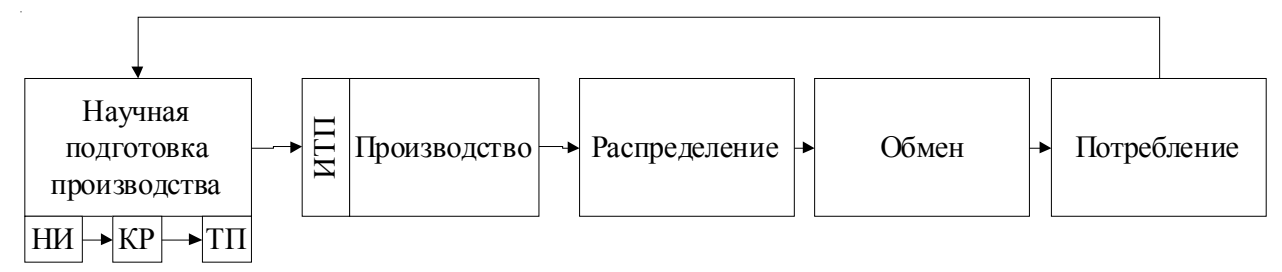

Рис. 3. Детализация предлагаемой схемы общественного воспроизводства

Примечание. Составлено авторами по материалам исследования.

выводом средств в офшорные юрисдикции. Для развития российской экономики очевидна необходимость скорейшего преобразования данной стадии воспроизводственного процесса. Современные цифровые технологии значительно изменяют и стадию обмена, способствуя снижению транзакционных издержек и повышению эффективности взаимодействий между экономическими субъектами. Заключительная стадия воспроизводства, потребление, также трансформируется, изменяются цели и способы потребления, совершенствуется как личное, так и производственное потребление.

Совокупность данных процессов приводит к возрастанию значимости социальных, трудовых, инновационных и технологических факторов, являющихся сегодня базой развития стран, переходящих к новым технологическим укладам. Выполненный анализ данных групп показателей развития российской экономики показал, что рост основных показателей пришелся на 2000-е гг., во многом это обстоятельство объясняется исключительно благоприятной конъюнктурой на энергетическом рынке. Вместе с тем ухудшение показателей в кризисные годы (1998-2000 гг., 20082010 гг., с 2014 г. по н. в.) показывает неустойчивость национальной экономической системы, что негативно отражается на ее конкурентоспособности. Сегодня в российской экономике существуют предпосылки для роста конкурентоспособности, однако успешность результатов находится в прямой зависимости от трансформации традиционной схемы общественного воспроизводства в России.

Современные тенденции в общественном воспроизводстве приводят также к необходимости выделения отдельной стадии процес$\mathrm{ca}-$ научной подготовки производства. Особое значение эта задача получает в связи с перспективным переходом России к пятому и шестому технологическим укладам, сопровождающимся расширенным воспроизводством на основе максимально эффективного использования человеческого капитала. Объективность перехода к инновационной (шумпетеровской) конкуренции в неоиндустриальной экономике приводит к выделению на стадии производства отдельного этапа институционально-технологического проектирования жизненного цикла товара, на котором формируется институционально-инновационная среда. Данные трансформации целесообразно рассматривать сегодня как теоретико-методологическую основу развития воспроизводственного процесса в российской экономике.

\section{ПРИМЕЧАНИЕ}

${ }^{1}$ Статья публикуется при поддержке гранта Российского фонда фундаментальных исследований (РФФИ) «Проблемы конфигурации глобальной экономики XXI века: идея социально-экономического прогресса и возможные интерпретации, № 18010-00877 A».

The reported article is funded by the grant of the Russian Foundation for Basic Research (RFBR) "Problems of the twenty-first Century Global Economy Configuration: The Idea of Socio-Economic Progress and Possible Interpretations, no. 18010-00877 A".

\section{СПИСОК ЛИТЕРАТУРЫ}

Авербух, В. М. Шестой технологический уклад и перспективы России. Краткий обзор / В. М. Авербух // Вестник Ставропольского государственного университета. - 2010. - № 71. - С. 159-166.

Глазьев, С. Ю. Теория долгосрочного технико-экономического развития / С. Ю. Глазьев. - М. : ВлаДар, 1993. - 310 c.

Кастро, Ф. Экономический и социальный кризис мира. Его последствия для развивающихся стран, его мрачные перспективы и необходи- 
мость бороться, если мы хотим выжить. Доклад, представленный VII Конференции глав государств и правительств неприсоединившихся стран / Ф. Кастро. - М. : Прогресс, 1983.C. 55-83.

Климова, В. В. Оценка воздействия технологических укладов на становление российской экономики / В. В. Климова // Экономический журнал. - 2010. - № 19. - С. 11-16.

Коновалова, М. Е. Технологическая многоукладность и ее роль в структурной сбалансированности российской экономики / М. Е. Коновалова // Проблемы современной экономики. - 2009. - № 1. - С. 88-90.

Проблемы социально-экономического развития России в условиях смены геоэкономической парадигмы / М. Л. Альпидовская [и др.]. Тверь : Тверской государственный университет, 2019. -287 c.

Толкачев, С. А. Институциональная среда конкуренции IT компаний / С. А. Толкачев, А. Ю. Тепляков // Научные исследования экономического факультета. Электронный журнал. - 2012. - № 1 (4). - С. 143-160.

Цикин, А. М. Формирование конкурентоспособности в условиях новых вызовов и ограничений / А. М. Цикин // Вестник ТвГУ. Серия: Экономика и управление. - 2017. - № 2. - С. 44-49.

Эггерсон, Р. Проблемы и институты / Р. Эггерсон. СПб. : Питер, 2001.-245 c.

Arthur, W. B. Increasing Returns and the New World of Business / W. B. Arthur // Harvard Business Review. - 1996. - Vol. 74, № 4. - P. 100-109.

Global Wage Report: Wage Inequality in the Workplace.-Geneva : ILO, 2016.-131 p.

Kleinknecht, A. The Non-Trivial Choice Between Innovation Indicators / A. Kleinknecht, K. Van Montfort, E. Brouwer // Economics of Innovation and New Technology. - 2002. Vol. 11, № 2. - P. 109-121.

Kormishkina, L. A. Economic Growth in Modern Russia: Problems and Prospects in the Context of Neo-Industrial Paradigm / L. A. Kormishkina, E. D. Kormishkin, D. A. Koloskov // Journal of Applied Economic Sciences. - 2016. - Vol. 11, № 6. - P. 1114-1128.

Kulkarni, D. The Processes of Scientific Discovery: The Strategy of Experimentation / D. Kulkarni, H. A. Simon // Cognitive Science. - 1988. - Vol. 12, № 2. - P. 139-175.

Mont, O. K. Clarifying the Concept of Product-Service System / O. K. Mont // Journal of Cleaner Production. - 2002. - Vol. 10, № 3. - P. 237-245.

Shefer, D. R\&D, Firm Size and Innovation: an Empirical Analysis / D. Shefer, A. Frenkel // Technovation.2005. - Vol. 25, № 1. - P. 25-32.
Thaler, R. H. Misbehaving: The Making of Behavioral Economics / R. H. Thaler, L. J. Ganser. - N. Y. : WW Norton, 2015. - 432 p.

\section{REFERENCES}

Averbukh V.M. Shestoy tekhnologicheskiy uklad i perspektivy Rossii. Kratkiy obzor [Sixth Technological Structure and Prospects of Russia. Short Review]. Vestnik Stavropolskogo gosudarstvennogo universiteta [Bulletin of Stavropol State University], 2010, no. 71, pp. 159-166.

Glazyev S.Yu. Teoriya dolgosrochnogo tekhnikoekonomicheskogo razvitiya [Theory of LongTerm Technical and Economic Development]. Moscow, VlaDar Publ., 1993. 310 p.

Kastro F. Ekonomicheskiy i sotsialnyy krizis mira. Ego posledstviya dlya razvivayushchikhsya stran, ego mrachnye perspektivy $i$ neobkhodimost borotsya, esli my khotim vyzhit. Doklad, predstavlennyy VII Konferentsii glav gosudarstv i pravitelstv neprisoedinivshikhsya stran [The Economic and Social Crisis of the World. Its Consequences for Developing Countries, Its Grim Prospects and the Need to Fight if We Want to Survive. Report Submitted to the $7^{\text {th }}$ Conference of Heads of State and Government of Non-Aligned Countries]. Moscow, Progress Publ., 1983, pp. 55-83.

Klimova V.V. Otsenka vozdeystviya tekhnologicheskikh ukladov na stanovlenie rossiyskoy ekonomiki [Evaluation of the Impact of Technological Structures on the Formation of the Russian Economy]. Economic Journal, 2010, no. 19, pp. 11-16.

Konovalova M.E. Tekhnologicheskaya mnogoukladnost i ee rol v strukturnoy sbalansirovannosti rossiyskoy ekonomiki [Technological Multistructure and Its Role in the Structural Balance of the Russian Economy]. Problems of Modern Economy, 2009, no. 1, pp. 88-90.

Alpidovskaya M.L., Tolkachev S.A., Sokolov D.P., Tsikin A.M. Problemy sotsialno-ekonomicheskogo razvitiya Rossii $v$ usloviyakh smeny geoekonomicheskoy paradigmy [Problems of Socio-Economic Development of Russia in the Context of a Change in the Geo-Economic Paradigm]. Tver, Tverskoy gosudarstvennyy universitet, 2019.287 p.

Tolkachev S.A., Teplyakov A.Yu. Institutsionalnaya sreda konkurentsii IT kompaniy [Institutional Environment of Competition of IT Companies]. Nauchnye issledovaniya ekonomicheskogo 
fakulteta. Elektronnyy zhurnal [Scientific Studies of the Faculty of Economics. Electronic Journal], 2012, no. 1 (4), pp. 143-160.

Tsikin A.M. Formirovanie konkurentosposobnosti v usloviyakh novykh vyzovov i ogranicheniy [Formation of Competitiveness in the Face of New Challenges and Limitations]. Vestnik TvGU. Seriya: Ekonomika i upravlenie [Bulletin of TvSU. Series: Economics and Management], 2017, no. 2, pp. 44-49.

Eggerson R. Problemy $i$ instituty [Problems and Institutions]. Saint Petersburg, Piter Publ., 2001. $245 \mathrm{p}$.

Arthur W.B. Increasing Returns and the New World of Business. Harvard Business Review, 1996, vol. 74, no. 4, pp. 100-109.

Global Wage Report: Wage Inequality in the Workplace. Geneva, ILO, 2016. 131 p.

Kleinknecht A., Van Montfort K., Brouwer E. The NonTrivial Choice Between Innovation Indicators.
Economics of Innovation and New Technology, 2002, vol. 11, no. 2, pp. 109-121.

Kormishkina L.A., Kormishkin E.D., Koloskov D.A. Economic Growth in Modern Russia: Problems and Prospects in the Context of Neo-Industrial Paradigm. Journal of Applied Economic Sciences, 2016, vol. 11, no. 6, pp. 1114-1128.

Kulkarni D., Simon H.A. The Processes of Scientific Discovery: The Strategy of Experimentation. Cognitive Science, 1988, vol. 12, no. 2, pp. 139-175.

Mont O.K. Clarifying the Concept of Product-Service System. Journal of Cleaner Production, 2002, vol. 10, no. 3, pp. 237-245.

Shefer D., Frenkel A. R\&D, Firm Size and Innovation: an Empirical Analysis. Technovation, 2005, vol. 25, no. 1, pp. 25-32.

Thaler R.H., Ganser L.J. Misbehaving: The Making of Behavioral Economics. New York, WW Norton, 2015. $432 \mathrm{p}$.

\section{Information About the Author}

Alexey M. Tsikin, Candidate of Sciences (Chemistry), Associate Professor, Department of Economic Theory, Financial University under the Government of the Russian Federation, Prosp. Leningradskiy, 49, 125993 Moscow, Russian Federation, AMTsikin@fa.ru, https://orcid.org/0000-0003-4383-0373

\section{Информация об авторе}

Алексей Максимович Цикин, кандидат химических наук, доцент Департамента экономической теории, Финансовый университет при Правительстве Российской Федерации, просп. Ленинградский, 49, 125993 г. Москва, Российская Федерация,AMTsikin@ffa.ru, https://orcid.org/0000-0003-4383-0373 